\title{
Cholestasis and liver failure with lambda-AL amyloidosis
}

\author{
F KONIKOFF, C MOR, S STERN, M SHAKLAI, J HALEVY, \\ AND E THEODOR
}

From the Department of Internal Medicine E, Department of Pathology and Division of Hematology, Beilinson Medical Center, Petah Tiqva, and the Sackler School of Medicine, Tel Aviv University, Israel.

SUMMARY Clinically significant liver involvement in systemic amyloidosis, especially with cholestasis, is rare. We report a case of primary amyloidosis with severe intrahepatic cholestasis leading to terminal liver failure. The present case is the first of its kind reported involving Lambda light chains only as the associated paraprotein. Conventional treatment and a therapeutic trial with dimethyl sulphoxide were unsuccessful.

The liver is known to be a common site of amyloid deposition, both in primary and secondary amyloidosis.' Hepatocellular failure and portal hypertension are rare, however, with cholestasis and jaundice found in only about $5 \%$ of cases. ${ }^{2}$ In primary amyloidosis with massive liver involvement the paraprotein consists characteristically of Kappa light chains. ${ }^{3}$ We report a case of primary amyloidosis of Lambda light chains with dominant liver involvement leading to cholestasis and terminal hepatic failure.

\section{CASE REPORT}

A 69 year old dentist was sent for evaluation of hepatomegaly found on a routine medical examination. He was asymptomatic and had been well throughout his life. On examination, a firm, nontender liver was palpated $8 \mathrm{~cm}$ beneath the right costal margin. The span was $19 \mathrm{~cm}$ on percussion. The tip of the spleen was palpable. Enlarged left axillary and bilateral inguinal lymph nodes were also palpated. The physical examination was otherwise unremarkable. A complete blood count (CBC), prothrombin time (PT), serum electrolytes, calcium, blood urea nitrogen (BUN), creatinine, albumin, globulin, alkaline phosphatase (ALP) and bilirubin were within normal limits. Serum aspartate amino-

Address for correspondence: Dr Fred Konikoff, Department of Internal Medicine E, Beilinson Medical Center, 49100 Petah Tiqva, Israel.

Received for publication 7 November 1986. transferase (AST) was $78 \mathrm{U} / \mathrm{l}$ and cholesterol 8.81 $\mathrm{mmol} / \mathrm{l}$. Urinalysis showed heavy proteinuria with a 24 hour protein excretion of $3.9 \mathrm{~g}$. Serum protein electrophoresis and immunoelectrophoresis revealed no $\mathrm{M}$ component, but in the urine Bence Jones protein was found, consisting of Lambda light chains. A bone marrow aspirate was hypercellular and showed $10 \%$ mature plasma cells with no evidence of myeloma, and a biopsy specimen of the marrow revealed amyloidosis.

The patient was treated with diuretics and except for occasional ankle swelling and fatigue he remained asymptomatic.

Four months later he was admitted for anorexia, pruritus, and jaundice of three days duration. On examination he was jaundiced with no signs of acute distress. The liver was palpated firm and non-tender $11 \mathrm{~cm}$ below the costal margin, with a span of $19 \mathrm{~cm}$. The spleen was felt $3 \mathrm{~cm}$ below the costal margin. There was slight ascites and marked pitting oedema of the lower extremities. Serum bilirubin was 289 $\mu \mathrm{mol} / \mathrm{l}$ (conjugated 235), AST $205 \mathrm{U} / \mathrm{l}$ and ALP 750 $\mathrm{U} / \mathrm{l}$ (mainly liver isoenzyme). Serum albumin was 25 $\mathrm{g} / \mathrm{l}$ and globulin $29 \mathrm{~g} / \mathrm{l}$. A CBC and PT were normal. Creatinine was $115 \mu \mathrm{mol} / \mathrm{l}$ and BUN $7.9 \mathrm{mmol} / \mathrm{l}$. An $M$ component was now detected in the serum and identified as free Lambda light chains. Serological tests for hepatitis A and B, cytomegalo- and EB-virus were negative. There was no history of ingestion of hepatotoxic drugs or chemicals. On ultrasound an 
enlarged homogenous liver was noted with no signs of intra or extrahepatic biliary obstruction. Neurologic examination, joints, skin, chest radiograph and echo-cardiography failed to reveal evidence of any other significant system involvement caused by amyloidosis.

The clinical course was rapidly progressive with deepening jaundice and deterioration of liver function. Treatment with diuretics, low sodium, high protein diet and occasional plasma replacement provided no relief. After obtaining informed consent, dimethyl sulphoxide (DMSO) $10 \mathrm{~g} / \mathrm{d}$ was added to the regime. After three weeks of ambulatory treatment, however, the patient continued to deteriorate and he was admitted with severe cholestasis (bilirubin $408 \mu \mathrm{mol} / \mathrm{l}$, conjugated 381) and oliguria. He died of hepatorenal failure within four days.

Autopsy revealed extensive amyloid deposits involving the liver, spleen, kidneys, lungs, adrenals, pancreas, lymph nodes, bone marrow, gastrointestinal tract and heart. The liver was firm and weighed $3250 \mathrm{~g}$. The gall bladder was normal and the biliary tract patent. No gall stones were found.

The histologic examination of the liver showed effacement of the normal architecture by extensive amyloid deposits confirmed by Congo red staining and the characteristic green birefringence on polarising microscopy. Paraffin sections of the liver biopsy were examined for immunoglobulin by an immunoperoxidase technique (indirect peroxidase conjugate method) ${ }^{4}$ with the use of trypsinisation. ${ }^{5}$ Staining for Lambda light chains was observed. No staining was seen for A, G, or M heavy chains nor for Kappa light chains. The distribution of amyloid was diffuse, with marked compression of liver cells (Fig. 1). In some fields it seemed to be more prominent in the intralobular areas while in others it was mainly periportal (Fig. 2). Bile staining of liver cells and bile thrombi were evident around periportal areas. Mild chronic inflammatory changes were noted in some portal spaces, but no proliferation of bile ducts was seen.

The spleen weighed $650 \mathrm{~g}$ and showed diffuse infiltration with amyloid. The bone marrow was cellular with hematopoietic cells of all three lines; in between, deposits of amyloid were found. There were no atypical plasma cells.

\section{Discussion}

As early as 1957 it was stated that liver involvement is very common in secondary amyloidosis and that it occurs in $30-40 \%$ of cases of primary disease. ${ }^{\circ}$ Later studies have shown that histologically the liver is practically always involved in systemic amyloidosis,

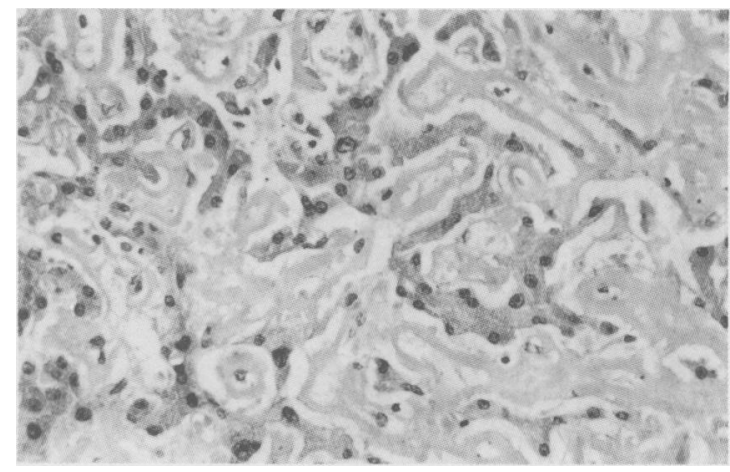

Fig. 1 Distorsion and compression atrophy of hepatocytes by amyloid deposits. $H$ and $E$.

whether primary or secondary, although the distribution and magnitude of amyloid deposition varies greatly. ${ }^{78}$ Clinically, however, amyloidosis rarely manifests as a liver disease ${ }^{y}$ and cholestasis with jaundice is seen in only about $5 \%$ of cases. ${ }^{2}$ In those unusual cases where liver involvement has been massive a Kappa-type light chain paraprotein has been found. ${ }^{3}$

Thus, the present case seems to be rare in at least two respects. Firstly, because of the severe cholestasis dominating the clinical course, and secondly, because of the paraprotein consisting of Lambda light chains only.

Among the cases of severe intrahepatic cholestasis caused by primary amyloidosis reported before 1978 , one was associated with IgG-Kappa and another with IgG-Lambda $\mathbf{M}$ component while for 10 others the available information is incomplete. ${ }^{2}$ Subsequently, two cases with IgG-Lambda," "I one with IgG$\mathrm{Kappa}^{12}$ and four with no recorded $\mathrm{M}$ component ${ }^{11-1+}$ have been reported. To our knowledge the present case is the only one reported with Lambda light chains only.

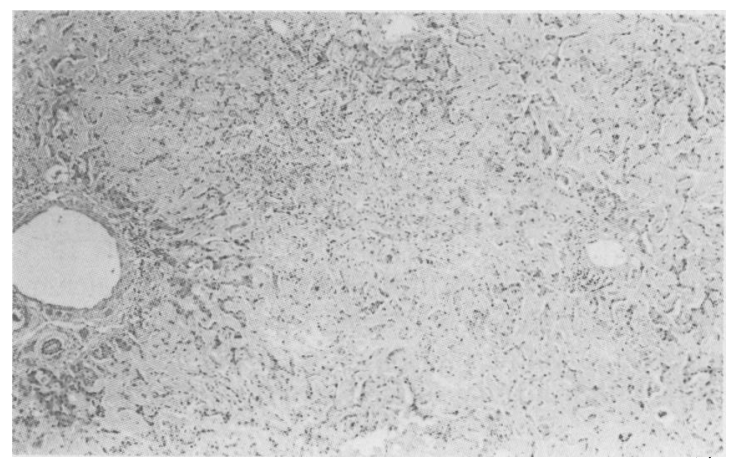

Fig. 2 Area of liver showing diffuse intralobular and periportal amyloidosis. $H$ and $E$. 
Previous investigators have tried to classify different forms of hepatic involvement in systemic amyloidosis. Levy et $a l^{15}$ stated that intralobular involvement seems to be distinct from portal involvement in producing massive hepatomegaly, ascites, high ALP concentrations and jaundice. In the review of cases with severe intrahepatic cholestasis by Rubinow et al, ${ }^{2}$ however, amyloid was found to be most prominent in periportal regions, and more recently, intrahepatic cholestasis with predominant pericentral deposition has been reported." Melato $e t$ $a l^{11}$ suggest that two different clinical and histologic courses can be differentiated. One with massive amyloid deposition and a slow clinical course, and another with less hepatic enlargement, but severe progressive intrahepatic cholestasis and a rapidly fatal course. The former group could further be specified by associated Kappa light chains, as suggested by the observations of Pras et al. ${ }^{3}$ Exceptions of this classification can be found as well, ${ }^{13}$ however, and there seems to be significant overlap between the different groups. The present case does not fit any of the proposed classifications either. Thus, additional information has to be sought in order to further define and understand hepatic involvement in amyloidosis. This might be achieved by means of histochemical, immunochemical and amino-acid sequence studies.

There is no successful treatment for primary amyloidosis. Although recently, some evidence favouring the use of melphalan and prednisone in systemic and hepatic primary amyloidosis is emerging $^{1617}$ at the time of treating this patient it was commonly accepted that this kind of therapy could not prolong survival ${ }^{18}$ and might even be hazardous. ${ }^{19}$ Moreover, in previous cases of cholestasis caused by amyloidosis melphalan and prednisone were not found to produce any favourable results. ${ }^{20-12}$ In the past few years beneficial effects of DMSO on secondary amyloidosis in experimental animals ${ }^{14}$ and $\operatorname{man}^{1516}$ have been reported. These facts, together with the relative safety of DMSO, prompted us to try the drug on our patient. No beneficial effects could, however, be noted in this case which might be because the treatment was started too late or that DMSO has no effect on primary amyloidosis. To evaluate the different treatment regimens for primary amyloidosis further controlled prospective long term studies are needed, especially in view of the grave prognosis of cases with a dominant cholestatic liver involvement.

In summary, this case shows a rare form of systemic amyloidosis - with dominant intrahepatic cholestasis and liver failure - being the first of its kind involving Lambda light chains only. It underscores the need to define clinical and laboratory criteria enabling earlier identification and treatment in a possibly reversible stage of this otherwise fatal condition.

\section{References}

1 Levine RA. Amyloid disease of the liver: correlation of clinical, functional and morphologic features in 47 patients. Am J Med 1962; 33: 349-57.

2 Rubinow A, Koff RS, Cohen AS. Severe intrahepatic cholestasis in primary amyloidosis. A report of four cases and a review of the literature. Am J Med 1978; 64: 937-46.

3 Pras M, Frangione B, Franklin EC. Isolated giant hepatomegaly - a clinical marker of AL-Kappa amyloidosis. Excerpta Medica International Congress Series, No. 497, 1979, 249-52.

4 Taylor CR. Immunoperoxidase techniques. Arch Pathol Lab Med 1978; 102: 113-21.

5 Mepam BL, Frater N, Mitchell BS. The use of proteolytic enzymes to improve immunoglobulin staining by the PAP technique. Histochem J 1979; 11: 345-57.

6 Bero GL. Amyloidosis: Its clinical and pathologic manifestations, with a report of 12 cases. Ann Intern Med 1957; 46: 931-55.

7 Cohen AS, Skinner M. Amyloidosis of the liver. In: Schiff L, Schiff ER, eds. Diseases of the liver. Philadelphia: Lippincott, 1982: 1081-99.

8 Chopra S, Rubinow A, Koff RS, Cohen AS. Hepatic amyloidosis. A histopathologic analysis of primary (AL) and secondary (AA) forms. Am J Pathol 1984; 115: 186-93.

9 Kyle RA, Greipp PR. Amyloidosis (AL). Clinical and laboratory features in 229 cases. Mayo Clin Proc 1983; 58: 665-83.

10 Finkelstein SD, Fornasier VL, Pruzanski W. Intrahepatic cholestasis with predominant pericentral deposition in systemic amyloidosis. Human Pathol 1981; 12: 470-2.

11 Melato M, Manconi R, Magris D, Morassi P, Gambel Berussi D, Tiribelli C. Different morphologic aspects and clinical features in massive hepatic amyloidosis. Digestion 1984; 29: 138-45.

12 Pirovino N, Altorfer J, Maranta E, Hammerli UP, Schmid M. Ikterus vom Typ der intrahepatischen Cholestase bei Amyloidose der Leber. Z Gastroenterol 1982; 20: 321-31.

13 Melkebeke P, Vandepitte J, Hannon R, Fevery J. Huge hepatomegaly, jaundice and portal hypertension due to amyloidosis of the liver. Digestion 1980; 20: 351-7.

14 Cox R. Amyloidosis of the liver causing jaundice. Postgrad Med J 1982; 58: 192-3.

15 Levy M, Polliack A, Lender M, Eliakim M. The liver in amyloidosis. Digestion 1974; 10: 40-51.

16 Kyle RA, Greipp PR, Garton JP, Gertz MA. Primary systemic amyloidosis. Comparison of melphalan/ prednisone versus colchicine. Am J Med 1985; 79: 708-16.

17 Gertz MA, Kyle RA. Response of primary hepatic amyloidosis to melphalan and prednisone: A case report and review of the literature. Mayo Clin Proc 1986; 61: 218-23. 
18 Kyle RA, Greipp PR. Primary systemic amyloidosis: comparison of melphalan and prednisone versus placebo. Blood 1978; 52: 818-27.

19 Kyle RA, Pierre RV, Bayrd ED. Primary amyloidosis and acute leukemia associated with melphalan therapy. Blood 1974; 44: 333-7.

20 Kedar I, Greenwald M, Ravid M. Treatment of experimental murine amyloidosis with dimethyl sulfoxide. Eur
J Clin Invest 1977; 7: 149-50.

21 Ravid M, Shapira J, Lang R, Kedar I. Prolonged dimethylsulphoxide treatment in 13 patients with systemic amyloidosis. Ann Rheum Dis 1982; 41: $587-92$.

22 Scheinberg MA, Pernambuco JC, Benson MD. DMSO and colchicine therapy in amyloid disease. Ann Rheum Dis 1984; 43: 421-3. 